\title{
Chapter 1. Land and Territory in the Austronesian World
}

\section{Thomas Reuter}

Contemporary societies within the South-East Asia-Pacific Region still maintain a distinctively Austronesian cultural perspective on land and territory. The present volume contributes to the comparative study of Austronesian societies by exploring this important theme of land and territory within their traditional cultures. At the same time, the authors acknowledge that these are cultures in transition and traditional relationships to land are increasingly compromised by the legal and administrative systems of modern nationstates in the region. This volume also contributes to a current debate in anthropology on the conflicting human tendencies of mobility and emplacement. In the context of this debate, many anthropologists have called for a greater focus on mobility to better reflect the increase in human mobility in the current postmodern period. The ethnographic evidence presented herein, however, shows that mobility is not just an issue in the study of contemporary cosmopolitan and migrant populations. A struggle with experiences of displacement and re-emplacement has been central to the historical experience of Austronesian societies for millennia. Many of the presumably 'traditional' models of society that have evolved from this struggle reflect a deep understanding of and appreciation for the formative historical influence of human mobility on society. These local models provide an alternative or, at least, some valuable inspirations for Western theories of society, which are only just beginning to afford a central place to the idea of 'cultures on the move'.

Austronesian-speaking peoples articulate their personal sense of belonging to particular places and lay claim to land or other territorial rights by invoking local histories of ancestral origins and migration. These accounts of human movement and emplacement might be written down but more often they are conveyed as oral histories. Origin histories are also inscribed on the physical landscape in the form of sacred sites, and on the minds of local participants through their shared experience of ritual performances held at these sites. Together these commemorative social practices generate a powerful sense of belonging and emplacement. There is also a strong emphasis on temporality and change. Clusters of settlements or ritual sites are linked through histories of human movement rather than being depicted as static arrays of bounded and separate places. A group and its place of belonging is usually constructed as a station on a pathway of ancestral migrations. People's rights to land or other localised resources and their social identity are thus inseparable, and both are 
defined by reference to time, or 'precedence'. Status and rights to land are indexed on their relative proximity to the sacred origin place or 'source' of this path, so that the ultimate ritual overlordship of a territory is often vested in the human representative of this source. At the same time, Austronesians also recognise the significance of secular power and the impact of political change on the historical trajectories of their societies and resource economies. Many origin narratives recognise and attempt to reconcile these conflicting value spheres of religious status and secular power within the models of society they create. According to these models, people share a collective ritual responsibility towards the Earth, which requires and promotes social cooperation. At the same time, they acknowledge that, as individuals with a strategic interest in a political economy based on agriculture, people also have a concern for dividing and controlling land. This volume explores these local models through a method of regional comparative ethnology, with the aim of identifying the key insights Austronesian societies have gained in their efforts to address some of the basic existential issues that arise from the relationship between people and land.

Austronesian-speaking societies occupy a vast and fairly cohesive area stretching from Taiwan to Madagascar and across South-East Asia, Micronesia and Melanesia into the Pacific, as far as Hawai'i, Easter Island and New Zealand. Austronesian societies share a common cultural heritage but have become widely dispersed through a long historical process of migration. In the course of this history of geographic dispersion and expansion, an immense diversity of linguistic and cultural forms was produced. This combination of a shared cultural base and a wide range of creative innovations provided a strong foundation for the meaningful comparative study of Austronesian societies. Recognising this comparative potential, a group of anthropologists around Professor James Fox, acting in collaboration with colleagues in archaeology, comparative linguistics and other disciplines, initiated the path-breaking Comparative Austronesian Studies Project at The Australian National University in the 1980s. Researchers attached to this project have published numerous individual papers as well as an important series of edited volumes (Fox 1993; Bellwood, Fox and Tryon 1995; Fox and Sather 1996; Fox 1997; Vischer, in press). Reflecting the unique research experiences of 14 leading Australian ethnographers in as many different Austronesian-speaking societies, from Sumatra to Tonga, the present contribution on land and territory is a further volume in this series.

Traditional ideas about land and territorial entitlements within the region have had to be renegotiated continuously in the past two centuries in response to a tumultuous history of colonisation and an often equally difficult process of incorporation within the legal and administrative structures of modernising, independent nationstates. Local people's traditional relationship to land also has been transformed by a gradual and accelerating process of globalisation, whereby concepts of traditional ownership increasingly come into conflict with the 
principles of an international, Western-dominated, late-capitalist economic and political system. One common type of conflict resulting from these changes is between indigenous peoples and the development agendas of modernising nationstates. Acting in conjunction with multinational corporations, national governments often have dismissed indigenous people's claims to collective ownership of traditional clan or village land and have legislated to reclassify such land as state-owned or private property. While we may focus on Austronesian traditions, the authors also explore some of these issues of social change. We thus hope to provide a useful resource to readers with an interest in contemporary political conflicts relating to traditional land rights in the Austronesian world and beyond.

In a traditional cultural context, Austronesian-speaking societies have constructed their sense of identity and legitimised their territorial claims to land and other resources by reference to local and sometimes regional origin narratives. These origin histories typically tell a tale either of gradual population growth and associated geographical expansion or of more spontaneous additions to the population with the sudden arrival of immigrants (invaders, refugees, affines or allies). In either case, the narratives tend to treat 'people' and 'land' as mutually constitutive categories within a single, place- and movement-oriented schema of ancestral identity and sacred geography. Place-based identities are commonly ranked in order of precedence, a concept of temporal order that draws precisely on the fact that different places and groups of people are linked through a history of ancestral migrations. The elements or stations in such pathways of identity are often remembered and narrated as long lists of placenames or 'topogenies' (Fox 1997: 8-12), rather than relying on genealogies, which allow people to trace ancestral connections by remembering the names of people. Historical ties between a set of places and resident communities may be commemorated also through complex systems of ritual visiting arrangements and asymmetric ceremonial exchange. Collective ritual performances, in a wide variety of forms, help to reinforce the religious character of this model of hierarchical emplacement by bringing it into the lived experience of the participants.

Their traditional sense of belonging to particular places, however, is much more than just a marker of identity and social status to the agriculturalist peoples of the Austronesian world. Land has also been, and continues to be, a primary economic resource and a matter of great strategic interest in its own right. Although there have been dramatic changes to patterns of land usage in recent times, evidence suggests the overall significance of land has not been declining in the region. The proportion of people engaged in subsistence agriculture may be shrinking, and with it some of the motivation for a religious perspective of land. The scarcity of land is increasing, however, and so are incidents of legal or political contestation of identity-based claims to ownership and usage rights. In this climate of increasing scarcity, old and new ways of thinking about land 
rights are clashing, sometimes violently. Conflicts frequently arise where village or clan land is appropriated by the State and made available to, for example, timber and mining companies or other development interests. Internal disputes are also common, especially where collectively owned land has been reclassified legally as individual private property and subsequently divided and sold off, to support consumer spending or for reinvestment into new means of production. The case studies in this volume document how Austronesians are attempting to negotiate changing relationships with the land at the nexus between a still relevant traditional way of life and the new rules that come into play as local societies are incorporated within nationalising and globalising political economies.

Local tensions between traditional and contemporary concepts of place raise the more general question of how we should conceptualise the changing relationship between people and land or 'place' within an economic and political context of globalisation and a cultural context often loosely referred to as the postmodern or late-capitalist condition. This condition is said to be characterised by an unprecedented degree of human mobility, migration, displacement and de-territorialisation. The case studies presented herein suggest, however, that many so-called traditional cultures have long and openly recognised human mobility and associated processes of social change as fundamental to the existence and historical development of society. Indeed, the idea of mobility has been central in defining identity and status relationships in the Austronesian world. Movement and migration lie at the very heart of their traditional models of emplacement, and also have been central to the historical experience on which these models are based. At the same time, the way in which place is conceptualised in Austronesian cultures also suggests that, no matter how much displacement they might experience, their relationships with the land, their place of origin and their place of residence are matters of utmost importance to all people, and no less so to a people on the move. Detailed ethnographic research and ethnological comparison is thus an essential step towards developing a better understanding of how different cultures have attempted to solve the fundamental conundrum of reconciling a basic human interest in mobility with a similarly fundamental interest in the security of emplacement.

In the remainder of this introduction, I will explore some of these theoretical and comparative issues in more detail, as well as providing an outline of the case studies in this volume.

\section{Land and Territory in the Context of Human Mobility and Globalisation: A Theoretical Debate and an Ethnological Solution}

Contemporary anthropological theorists have moved away from an earlier tendency to view cultures as social systems localised in specific places or territories. Space had sometimes served as a convenient metaphor to articulate 
a clear and lasting division of the world, assigning to each distinguishable culture its unique and original place - a cultural habitat based on a coincidence of spatial separation and cultural difference. Some authors have directed their critique at the 'incarceration' cultures in fixed places (Appadurai 1988) and others at the metaphor of the 'localness' of cultures (Clifford 1988), or at the latent functionalist search for cultural stability and social equilibrium (Malkki 1995).

One reason why this habitual linking of culture and topology, of nation and territory, became the focus of much critical analysis was the increasing mobility of culture and people on an unprecedented scale in the 20th century. While still appreciating the merits of detailed ethnographic research, most contemporary theorists now insist that cultures need to be understood as systems in motion. An increasing number of ethnographers are following this advice and are turning away from classical, localised fieldwork to conduct studies of human mobility. Some study loosely connected groups of tourists, itinerant workers, asylum-seekers and migrants, while others observe the confluence of cultural traditions in diasporal, expatriate and multicultural communities (e.g. Lavie and Swedenburg 1996). This new body of anthropological research does indeed show that in today's world of electronic communication and mass movement, a culture can no longer be associated exclusively with a single place or assigned a definitive homeland, let alone confined within narrowly conceived territorial boundaries. Studies of transnational and intra-national migration, for example, raise questions about how to assign a spatial referent to groups of people whose identity is situated somewhere in between the places of their origin and current residence.

At the same time, it would seem futile to try to deny the basic localising constraints of the human condition. As embodied individuals, we necessarily operate in specific physical environments wherein many of our most important social interactions must take place. Direct face-to-face interaction is dependent largely on the language and other culture-specific codes operative within such a local setting. Even if we accept the postmodernist hypothesis that there is a global trend towards a hybridisation of cultures, there is as yet no universally intelligible language, and the local use of interactive codes is never arbitrary even where multiple codes have become available. Other than exerting an influence on how we satisfy our immediate social and communicative interests, the human condition of situated embodiment also tends to propel us to look locally for resources to satisfy some of our most immediate material interests. One of these interests is to own, borrow or lease a territory or 'socially demarcated place' that provides shelter, security and perhaps a source of income.

There are numerous studies on the social construction of place and landscape and on the symbology and politics of space, which all suggest that territory is still very much something humans are prepared to contest, no matter whether the claims to the territory are material or symbolic, political or religious, historical 
or mythological. Ironically, new research with a focus on movement - whether it has looked at cases of voluntary displacement or forceful eviction-has raised our awareness of the importance and cultural process of constructing spaces, localities and associated identities (Gupta and Ferguson 1992). The image of a place or country of origin is often vigorously cultivated by, for example, people living in a diaspora setting. Memories of home are carefully maintained, and not just as a matter of nostalgia. Access to social networks created by transnational emigration, for example, can serve as an economic resource or as a means for generating influence and power in relation to the nation state (Marcus 1993). Ever-new places of mythical origin and pathways of migration are thus being imagined and lived in, and they are often the subject of disputes within and across local social contexts.

The debate about changing relationships between people and places in anthropology reflects on a number of important political issues, trends and events of global importance. The new trend towards research on the mobility of cultures may in part reflect our own lived experience of a postmodern condition of de-territorialisation, which has been brought about by increased mobility, information exchange and a new political economy, incorporating a global system of finance, production, promotion and consumption. To point out how physical displacement through mass migration, social atomisation and the rise of fluid, consumption-based identities have changed our lives, however, is to tell only one half of the story of what might constitute the typical contemporary experience of culture. In this same historical period, we have witnessed a series of conflicts in the Balkans, the Middle East, Africa, the former Soviet Union and elsewhere, which have highlighted the enduring importance of culture and ethnicity in the legitimisation of claims over territories and localised resources. The so-called 'War on Terror', the largest of these contemporary conflicts and the one most likely to preoccupy the world for decades to come, likewise draws on ideas of cultural or religious difference. While it is not portrayed as a territorial war, the underlying struggle in this presumed 'clash of civilisations' seems to be for the control of localised material resources such as oil reserves. Similarly, the enduring appeal of a defensive territorial attitude is also evident in the recent political history of many Western nations, including Australia, Denmark and Italy, where a 'tough stance' on refugees and on other immigration issues has delivered a succession of election victories to conservative governments in the first decade of this new millennium.

These global political trends illustrate the resilience of ethnic and cultural ideas of difference and their strategic function in resource conflicts. Even authors who strongly advocate the study of human mobility and displacement in a globalising world have commented on this stubborn persistence of territorial conflicts (e.g., Olwig and Hastrup 1997: 4). One obvious reason for the resilience of cultural constructs of emplacement is the paramount value of such constructs 
as a means of legitimising exclusive or privileged control over land and other important material resources. In my view, however, the mere fact that strategic discourses of identity can be useful in resource conflicts does not support the radical constructivist argument that such conflicts are entirely a product of ideology. Resource competition is not contingent on cultural constructs. And, in any case, cultural constructs of place and identity can be just as important for conflict resolution. Despite their strategic legitimising function, shared concepts of identity and emplacement can help to regulate the distribution of local resources among different groups of people and can thus reduce the potential for violent conflict among them. This more positive aspect provides an additional incentive for the cross-cultural study of discourses of emplacement and associated systems of local resource distribution - assuming we accept the basic anthropological idea that there is something we can learn from other societies by looking at how they have attempted to resolve a perennial existential challenge that we too must face.

This volume thus has much to contribute to the debate in current anthropology on the mobility and territoriality of human cultures. It does so by exploring how for centuries people in 14 of the numerous historically and linguistically related societies of the vast Austronesian world have dealt with the very same underlying issues that seem to so concern the postmodern world. The most fundamental of these issues are: first, the dynamic tension between the simultaneous human tendencies towards mobility and emplacement, and second, the link between territorial claims for material resources and the social identity constructs that legitimise and regulate these claims. I will refer to these two as 'the mobility issue' and 'the legitimacy issue' respectively.

Austronesian social categories of land and discourses about land claims exemplify how the basic issues of mobility and legitimacy have been negotiated in the societies of this region. Like all social systems, Austronesian societies have devised a system for accommodating the inevitable conflicts to do with 'carving up the land' while simultaneously allowing people to 'share the earth', by finding ways to avoid or reduce violent confrontations in the context of resource competition. By exploring the nuanced strategies Austronesian societies have developed over many centuries, the papers in this volume illustrate that mobility is not really a new issue at all. In the Austronesian world, at least, migration has long been a standard response to tensions arising from population change and resource scarcity in a given locality, and to the allure of finding more abundant resources elsewhere through migration.

Austronesians have always been remarkably mobile, as is evident from their history of continual migration, originating in southern China and moving in numerous waves via Taiwan across the far-flung islands of the Indian and Pacific Oceans. Perhaps it is this remarkable mobility that has inspired them to turn 
human mobility into the conceptual backbone of a social philosophy wherein concepts of 'origin' and 'precedence' are the most central constructs.

The concepts of origin and precedence reflect the fact that people on the move will necessarily encounter others who have preceded them and already lay claim to the land to some degree. Various local origin narratives acknowledge that there are different ways in which these earlier settlers can respond to the arrival of newcomers, ranging from assimilation at the margins to accommodation into the very centre of local society. They also illustrate how widely the outcomes of such encounters can range depending on the attitude and power of the newcomers, who might seek a culturally mediated agreement on how to share the land and other material and symbolic resources with earlier settlers, or who might violently or treacherously usurp the precedence claims of the latter.

All in all, Austronesian ideas about people and land show an appreciation that society is the sediment of human movements and, indeed, that life itself is predicated on movement. An example of this celebration of movement in a social context is the appreciation Austronesians tend to show for the 'flow of life' that occurs in the context of marriage exchanges between exogamous groups (see Fox 1980). The idea of culture-in-motion, arising from the interplay between time, place and human action, is thus the central idiom of Austronesians' 'models of' their own societies, and of the cosmos as a whole. At the same time, these are also 'models for', insofar as they are designed to cope with the potential for conflict over land and other local resources.

A detailed discussion of the comparative ethnology of Austronesian models of movement and emplacement is provided in the postscript of this volume. In order to better appreciate the thematic connections between the papers, however, some of the main features and implications of these cultural models of social space need to be identified in advance.

\section{The Social Construction of Land, Place and Territory in the Austronesian World: From Ethnography to Comparative Ethnology}

Although they are dispersed widely, from Sumatra in the west to Tonga in the east, the 14 societies discussed in this volume share a common cultural and historical heritage. Linguistic, biological, archaeological and anthropological evidence shows that contemporary Austronesian-speaking societies have a common origin and history of dispersion. This history can be traced back some 6,000 years, to when their ancestors began a long series of migrations from southern China via Taiwan to South-East Asia and onward to Madagascar, Micronesia, Melanesia, Polynesia and New Zealand (Bellwood, Fox and Tryon 1995). This history of migration was accompanied by continuous cultural adaptations and transformations. There were also long-term interactions with 
earlier inhabitants and their cultures - in Halmahera and Melanesia, for example - which sometimes led to the assimilation of Austronesian languages and culture by other populations. Today more than 1,000 different Austronesian languages are spoken by an estimated 270 million people in this vast region.

The linguistic diversity of these societies is matched by their cultural diversity, and the preceding volumes in the Comparative Austronesia Project series since 1993 have illustrated some of this staggering variety of social forms. The shared Austronesian heritage of these societies is, however equally evident. Two of the most important dimensions of this shared cultural heritage were described in the first volume of this series, The Austronesians: Historical and Comparative Perspectives, as a common tendency towards

the tracing of local origins and the reliance on a variety of narratives for the construction of a shared past. Thus the sharing of a journey may be used to define relatedness whereas claims to precedence, often based on the order of events in particular narratives, figure prominently as a means of defining social difference. (Bellwood, Fox and Tryon 1995: 10)

Social history tends to be depicted as a temporal sequence of events identified with named locations, which are all part of the pathway of an ancestral journey and can be ranked according to their proximity to the point of origin. This often gives rise to place-based models of human relatedness or 'topogenies', to use a term introduced by James Fox in another of these earlier volumes, The Poetic Power of Place (1997). Rather than or in addition to using genealogies in which named personal ancestors are used to establish connections between the living, many Austronesian societies rely on lists of placenames or topogenies to establish historical links between groups of people within and across different localities in a region. Topogenies are thus narrative accounts of a complex history of human movement and emplacement. Topogenies are used to explain (and often also to contest) how contemporary societies came to be grouped and status differentiated as they are today.

In Austronesian-speaking societies, the most salient social categories are often based on cohabitation or shared usage of a named area of residential or agricultural land by a particular group of people. One reason why place is such a common, convenient and powerful marker of identity, in the Austronesian world and beyond, is that the membership of place-based groups need not be homogenous. Whether they are ancestral origin houses, named settlements, domains or regional ritual federations, place-based social categories are very useful to societies with a complex history of human migration and relocation. The complexity created by movement demands a social capacity for maintaining unity in the face of diversity at the local level. At the same time, co-residents will usually compete for the control of local resources to some degree. This creates a tendency to construct a system of social differentiation by stressing 
diversity of origins in other contexts to serve as a status marker. The Austronesian model for this simultaneous sharing and dividing of the land focuses on human movement and utilises associated ideas of precedence as the main classificatory principle for regulating access to land.

The topogenies of Austronesian societies are therefore valorised as 'moral' spaces wherein individual locations are not simply distinguished but are ranked in order of precedence, as are the people whose identities are indexed to these locations (Fox 1997: 4). This suggests that - although it may often be owned collectively within localised groups - the way land is shared is neither free and unproblematic nor necessarily equitable in Austronesian societies. Land has indeed been the single most important material resource, and land rights have constituted a primary privilege in the predominantly agriculture-based political economies of this region.

The balance between the value of the privileges and the cost of the obligations attached to land usage rights is variable across different communities depending on demographic and other factors. A need to restrict access to land ownership or usage rights has been felt most frequently in cases where population growth within an expanding system of segmentary social organisation has led to a local scarcity of agricultural land and a corresponding increase in value. Maintaining privileged access to land through claims of precedence was not only about securing land for personal use. Even under conditions of relative abundance, land was still valuable because any excess could be distributed profitably to client newcomers in return for ritual or political allegiance. In future, land scarcity seems set to become a more or less continuous condition and will reach an unprecedented pitch as land values continue to increase across the South-East Asia-Pacific region. The discursive space between place and identity is likely to become more and more contested and politicised as a result.

Variations in resource scarcity are an important aspect of the operating conditions of all human societies, and Austronesian societies are not unique in this sense. As far as these fluctuations are concerned, Austronesian societies can differ more from one another, and vary more within themselves over time, than they differ from many non-Austronesian societies at any given time. What makes human societies unique are not fluctuations in the existential problems they face in managing finite resources but the distinctive cultural strategies they develop for distributing these resources and for mediating resource conflicts whenever they arise.

The Austronesian model of emplacement through narratives of movement is one such strategy. The distinguishing feature of this model is that it typically creates a fluid and evolving system of social differentiation based on a principle of precedence ranking which, in turn, is predicated on a fundamental assumption of human mobility in a context of segmentary expansion or migration. The main 
task of this comparative volume, then, is to spell out how this basic concept of emplacement through growth and movement plays out in different Austronesian societies - under a variety of different operating conditions and as a result of continual cultural innovation - to produce a wide range of comparable social formations of variable size and character.

Most of the papers in this volume were first presented at a workshop held on June 18-19, 2001 at The Australian National University in Canberra, Australia, entitled 'Sharing the Earth, Dividing the Land: Territorial Categories and Institutions in the Austronesian World'. The aim of the workshop was to identify and discuss common categories, organisational principles and historical processes of innovation among related populations in different parts of this region. Participants were asked to describe territorial institutions of varying size in the societies they had studied, from house or longhouse territories to the more extensive lands belonging to a hamlet or village, and to look at how these different layers of territorial organisation interrelated conceptually and institutionally. Special attention was to be paid to larger, regional institutions such as domains, chiefdoms or polities, which tended to be composed of several of the smaller territorial units and might, in turn, have provided the building blocks for early state formation in the region.

Four important dimensions for the comparison of Austronesian models of emplacement could be identified in subsequent discussions, and each of these were exemplified by several of the case studies in this volume. These comparative dimensions concern: 1) the territorial categories of Austronesian languages; 2) the specific metaphors that characterise Austronesian models of emplacement and social identity; 3) how ceremonial domains have been transformed by, and also contributed to, the formation of more complex polities, and 4) how traditional ways of relating to the land are being challenged within the context of modern nationstates and their globalising economies.

\section{Austronesian Territorial Categories}

The terminology we use to designate different territories and social relations to land in Western societies - words such as 'estate', 'village', 'domain', 'territory', 'proprietor', 'tenant' and their reflexes in other European languages - are not suitable to serve as universal categories for the purposes of cross-cultural comparison. The meanings of these terms are embedded irrevocably in a distinctly European political history and legal tradition, and even within that tradition there is much heterogeneity. It may be impossible to avoid completely the use of these loaded terms in the act of translation. It is possible and indeed imperative, however, to develop an appreciation for the semantics and pragmatics of local categories. 
The meaning of key terms within a society arises from their conceptual relation to the local cosmology and idiom wherein they are embedded, and their pragmatic use is revealed in relation to local behavioural models for the pursuit of communicative and strategic interests. 'Territorial categories' in Austronesian societies thus need to be understood in the context of a culture-specific perception of land and a rationale for legitimising land ownership, which, in turn, is associated with a specific pattern of social organisation. These considerations have prompted the authors to approach the task of comparative analysis by exploring the relevant indigenous Austronesian categories, rather than imposing a set of alien categories derived from a European tradition of political history and social science.

Comparison has revealed that, with few exceptions (see below), words used by speakers of contemporary Austronesian languages to designate named tracts of land are reflexes of just three Proto-Austronesian reconstructions. Variations in the actual meaning of these related terms are somewhat more pronounced. For example, the size of the units of land referred to by the same set of reflexes differs across cultures, as does the relative emphasis placed on centres versus boundaries in defining these units. Their meaning within the general local model of relations-between humans and the land, and among 'emplaced humans' - however, remains fairly consistent. At a more pragmatic level, finally, the comparison has exposed substantial variation in the practical significance these traditional territorial terms carry across contemporary Austronesian societies, particularly in view of major political and economic changes in their recent history.

Three sets of reflexes are of particular interest in exploring categories of people and land due to their wide distribution and pivotal social significance in Austronesian languages and societies. The first set are reflexes of the Proto-Austronesian (PAN) reconstruction *banua (banua, banwa, wanua, vanua, fanua, panua, manua, banuah, banuwa, banwa, binua, bonua, menoa, nua, knua, fua, whenua, hena, fena). The reflexes of *banua are variable in their meaning across different languages and contexts, but generally refer to a designated 'stretch of land', 'territory' or 'dwelling place' of varying size, and/or to the inhabitants of such a place. Two other sets of reflexes that carry a similar meaning are reflexes of the reconstructions *tanah (tana, tanaq, taneq, taneh, tano, 'ano) and *daya (darat, dare, dae, rae, rai). James Fox considers these sets of reflexes and their variable semantic contents in more detail in his postscript. It is important, however, to discuss in advance some of the implications of these linguistic family resemblances among Austronesian populations.

It would be easy to succumb to a sense of frustration as one tries to pinpoint the actual significance and limits of the link between linguistic and cultural similarities within this region and in general. The problem with the idea of a 
comparative ethnology based on comparative linguistics, as so often in social theory, is not really that the link between language and culture is intrinsically ambiguous or indeterminate. It is simply extremely complex. Without delving into the depths of communication theory, and for the specific purposes of this present discussion, one way to account for a good part of this complexity is to adopt a socio-historical perspective to comparative ethnology. This approach assumes, first, that the link between words and their meaning is fundamentally arbitrary, and, second, that the link, such as it is, is socially constructed over time among populations of regularly communicating individuals. Once constructed, the link can be very durable, so that contemporary reflexes of a word may retain much of the original meaning for centuries, even millennia. A total loss or reassignment of meaning is also possible, however, and subtle fluctuations occur all the time. An incentive for changing the meaning of words might arise, for example, from gradual or sudden changes in a people's way of life, their environment, economic activities and relations with other populations.

The relationship between language and social history is clearly significant insofar as systematic similarities between languages, and even loan words, are always the sediment of historical connections or interactions, including migration, conquest, trade and individual travel. At the same time, the use of similar terms in different societies is insufficient in itself to serve as a predictor of specific cultural similarities because there is a constant drift in the local meaning of terms, which is a function of their embeddedness within ever-evolving social contexts. This drift may explain why the social performance of cultural meaning is often less conservative than the social performance of words as signs in a given language.

What does this entail for the present set of Austronesian case studies? By definition, linguistic connections can be traced between any two Austronesian languages, and this reflects the historical fact that the speakers of these languages are related populations and the sociological fact that language tends to be conservative. This does not provide a guarantee that the two societies will also show cultural similarities. Nevertheless, it is very likely indeed that they will, given that the link between words and their meanings is also quite conservative, especially with very basic words such as 'land' or 'house'. Similarly, there can be no guarantee that societies whose members speak closely related languages are culturally more similar than speakers of more distantly related languages within the same family. Looking at the case studies in this volume, for example, one could point out that the languages of Buru, Seram, Banda, Sikka, Keo and Timor all fall within the Central Malayo-Polynesian Group, those of Bali and Sumatra within the Western Malayo-Polynesian Group, and those of North Mekeo, North Pentecost, Ambrym and Tonga in the Oceanic Group of Austronesian languages. I would argue, however, that the comparative evidence so far is insufficient to support a claim that cultural similarities are greater among 
societies within than across these language groups. Other factors, such a geographic proximity and ease of interaction between populations, are as, or more, important in this context.

It also needs to be considered that throughout the region new terms with initially quite foreign meanings were introduced to refer to territorially defined administrative units within early Indic states, coastal trading polities, colonial states or independent modern nation states. The local meaning and social significance of an introduced term, such as the Sanskrit word desa ('village') in Indonesia, for example, can match that of earlier, local Austronesian terms (banua in this case) more closely than it matches the meaning and social significance of the same term in the original language and society from which it is derived. This semantic localisation of introduced terms can be a complex historical process. In the part of the region that came under the influence of Indic kingdoms, for example, terms first introduced as Sanskrit loan words (desa, kuta, negara) were later adopted and heavily reinterpreted by modern nation states such as the Republic of Indonesia. Their usage has spread correspondingly, within the new boundaries of these nation states and far beyond the geographic reach of the early Indic kingdoms that first adopted them. Thus the term desa (dinas), for example, reached West Papua only in the 1950s, and only as the designation for a modern, Indonesian administrative structure. In Bali the situation is more complicated (Reuter 1999). Here the classical Indonesian adaptation of the Indic term desa still exists, referring to the 'desa adat', an institution that has survived from the times of Bali's early Hindu polities. This more traditional desa coexists and competes for significance with the same modern Indonesian administrative unit we now also find on Buru. The latter is referred to as the desa dinas in Bali in order to distinguish it from the desa adat.

In many contemporary Austronesian societies, modern territorial terms and associated administrative units thus coexist with earlier schemata for the social construction and division of space. The physical boundaries of these old and new categories may or may not coincide, though there is often some degree of continuity. Conflicts tend to arise when new administrative boundaries divide people who consider themselves historically related and part of a social whole or, conversely, throw together people who do not have any recognised traditional connections.

\section{Metaphors of Socio-Spatial Relations}

Metaphors of socio-spatial relations, like all metaphors, are figures of speech whereby a thing is spoken of as being that which it only resembles. The metaphors Austronesians use to imagine and reflect on the social structure of a domain or similar socio-territorial unit show striking similarities. Again, this suggests that the usage of such metaphors tends to be rather conservative, 
notwithstanding the fact that their meaning and social implications will vary from one society to the next.

Botanic metaphors are among the most commonly used metaphors for social relationships in the Austronesian world. The source ancestor of a clan or founding clan of a village, for example, may be referred to as the 'trunk' or 'root' and his descendant or newcomer clients as the 'leaves' or 'tips' of the same tree. Similarly in a topogeny, the place of origin is usually the ritual centre or 'trunk' of the domain, to which a path of origin is ceremonially traced back along one or several 'branch' villages, beginning from the newest settlements or 'tips'. The people who reside at, or in some other way can lay claim to, the origin site tend to maintain a position of ritual precedence or of political authority in the domain, but rarely both. Botanic metaphors generally suggest a segmentary process of spatial expansion due to organic growth from within, but can and are applied also within local societies featuring a population with multiple origins.

Body metaphors are also used widely for the imagery of social space in the Austronesian world. In highland Bali, for example, differently ranked members of the village council of elders are associated with specific body parts of sacrificial animals, which are divided among them to be consumed during ritual meals. Indeed, some of the titles of elders are derived from body parts, especially from the divisions of the forelegs (Reuter 2002a, 2002b). The 'head' of domains is often associated with the most upstream inhabited locations at the source of river systems. Left and right body halves are often associated with ceremonial moieties or other forms of dual social categories. The four extremities of sacrificial animals, finally, tend to be associated with some form of fourfold division of space and society (see Mosko, this volume), which is also a common pattern within the region.

Of all the metaphors used to conceptualise socio-territorial units in Austronesian societies, the most important is that of a 'path' or 'journey'; a trajectory of human movement through space and time. The significance of mytho-historical movements through space is evident particularly in the cosmological organisation of larger, regional socio-territorial units, including ritual domains and pre-colonial kingdoms. Such domains and polities tend to be composed of smaller units linked together by a history of ancestral migration, beginning at a shared point of origin or, sometimes, ending at a shared destination, which is then transformed into a point of origin for all future purposes (see Winn, this volume).

An idiom of relatedness based on kinship and marriage is also used frequently to conceptualise the unity and divisions of local society, along with the boundaries and divisions of land claimed by various groups. Among highland Balinese, for example, historical ties between villages are often expressed figuratively by postulating asymmetric kinship relationships between village 
ancestor deities. Often the physical landscape contributes to, and is subsumed within, the imagery of a more complex socio-physical totality that is attributed with a numinous quality. In such an integrated world, the land and its people are so tightly interwoven that it is futile to try to discuss social categories without reference to categories of land, and vice versa.

\section{From Ritual Domains to States: Scales of Complexity}

There is considerable variability in the relative complexity of land-related categories and land tenure arrangements in Austronesian societies. Among other factors, these variations seem to depend on: a) the relative abundance of land and the general conduciveness of ecological and climatic conditions to intensive agriculture on that land; b) the population density; c) the social diversity, especially in terms of the presence or absence of immigrants (in small or large numbers; with or without a separate ethnic identity, language or religion; with or without colonial or modern state sponsorship); d) the degree of local access to regional or international trade networks; and e) the degree of direct foreign intervention in local affairs. More complex social and political systems might have evolved first in areas that could sustain large and dense populations through intensive agriculture, division of labour or trade, or where an influx of migrants necessitated more complex models of emplacement.

It is likely that some of the larger, regional systems of Austronesian socio-territorial organisation provided a foundation for the formation of polities and early states. While local developmental processes might have been enough to create social systems of considerable size and complexity in their own right, it is evident that the first major states did not build on the logic of an indigenous Austronesian social system and cosmology alone. This is true particularly for the greater part of South-East Asia, which has been subject to Indic influence at some time.

A number of the large Hindu-Buddhist polities emerging in the region from the fifth century onward employed Indic notions of divine kingship in order to generate an inter-local form of organisation for the first time in a particular area. Others appear to have utilised and transformed pre-existing, though perhaps hitherto predominantly ritual, forms of regional organisation in order to create a more cohesive and centralised political system or 'state' (negara), though still with a strong ritual component (Geertz 1980). In other cases again, there might have been hostility, avoidance or some kind of truce between people with a stake in an earlier system of regional socio-territorial organisation and encroaching Hindu-Buddhist (and later Muslim) polities that were seeking to establish some degree of sovereignty over their territory (Reuter 2002a). The polities that developed in Tonga and elsewhere in the Pacific, finally, appear to have evolved initially without any direct foreign influence. 
All of the case studies presented in this book, however, provide evidence of how people's traditional ways of categorising and regulating access to land were profoundly transformed, once again or for the first time, by their incorporation into the political, administrative and legal systems of colonial empires and/or, more recently, independent modern nation states. The transformations tended to be more incisive than those of earlier periods. Earlier Indic and Muslim states grew out of trade links accompanied by the importation of foreign religions and associated concepts of sovereignty, but essentially had to be built on local foundations to some degree. Colonial states, while they too might have begun as trading ventures, were ultimately built on military conquest or control, and involved the establishment of a government apparatus led by foreigners. Nevertheless, local forms of social and political organisation were maintained as a support structure in many cases, due to the limited resources of the expatriates in many colonial states. This kind of collaboration eventually produced Western-educated local elites who later led the anti-colonial struggle and put themselves at the head of the newly emerging independent states in the region. In cases where such collaboration was limited and colonial rule was more direct, earlier models of land tenure might have all but disappeared.

In many contemporary societies in the Austronesian world, one therefore finds a complex layered patchwork of territorial and other social institutions that can be traced to various stages in a historical movement towards ever-increasing complexity. I will later return to the question of how relevant Austronesian territorial categories still are in the context of complex modern nation states with rapidly globalising economies.

\section{Outline}

The ethnographic case studies in this volume are presented in geographical order from the west moving eastward. Each paper contributes to several of the comparative themes identified above. A brief description of the content of each case study is provided in advance in order to identify which of these themes they are most relevant to. These descriptions also reveal some of the unique variations and less obvious commonalities in the ways different Austronesian societies have approached the basic social issue of regulating the relationship between people and land.

In the first paper, Minako Sakai discusses the 'Kute' as an indigenous territorial category and institution in South Sumatra (Chapter Two). The Sanskrit-derived Old Malay word kute ('a fortified town or palace') was used widely in the highlands of South Sumatra. The author examines how the term and the category 'kute' survived by looking at the case of the Gumai. At a level of state administration, kute has been replaced with a succession of other terms, including marga, dusun, and finally, desa. Like kute itself, these newer terms have acquired some of the meaning of an underlying Austronesian territorial concept that 
envisages a shared social identity based on a specific 'foundation event'. Many Gumai villages in the South Sumatran highlands are thought to have been established by, and thus trace their 'origin' to, a single ancestor, the Puyang Ketunggalan Dusun. Villages contained a small ancestor house (lunjuk or rumah puyang) for the spirits of the founding ancestors, where rituals would be held to commemorate the village origins. The morpheme $p u$ in puyang could be a reflex of puqun, which is a Proto-Malayo-Polynesian reconstruction meaning 'tree', 'trunk', 'base' or 'source'. Villages are inhabited by the descendants of the puyang and their affines. The population is divided into origin groups called jungkuk which are ranked in order of precedence based on birth order and ritual seniority.

My own paper (Chapter Three), Ritual Domains and Communal Land in the Highlands of Bali, explores the significance of ceremonial domains (banua) among highland Balinese. Banua, in Bali, are ritually defined regional territories of variable size. About 15 of these domains have been identified, studied and compared by the author. Each is under the spiritual protection of the deified ancestors who first cleared the forest and established settlements. These ancestral deities are located in village temples. The temple of the oldest settlement in a domain is gradually transformed into a regional temple where the most senior ancestors are venerated by people from all branch villages within the domain. Origin myths and rituals retrace the path of the first ancestors, their emigrating descendants or new immigrants, thus creating the image of a complex land-and time-scape that has been inscribed and is perpetually re-inscribed by human action. Despite their focus on origin histories, regional ritual alliances among villages are voluntary associations, and the status distribution among participants is fluid and contested.

Status relations among villages in a domain are defined by notions of precedence and are thus asymmetric. This has few economic implications in contemporary banua. Ritual status differences between households within a village do, however, have such implications. Only village-founder households have access to land owned collectively by the village (tanah desa) and administered by a council of elders (kerama desa), who are seated in order of precedence in the village longhouse (descending in rank from the 'tip' to the 'trunk' end). Claims to village-founder status, furthermore, necessarily draw on the origin narratives of the domain of which the village is a part.

A case study of a local origin myth is used to show that the historical transformation of a village into a much more complex regional domain coincides with a shift from material to symbolic resources as the object of primary concern. The idea of a shared land or territory is retained and commemorated in a ritual context, even when individual villages have already gained independence in all practical matters in the course of this transformation. The shift to a 
predominant concern with symbolic resources is underpinned by a desire to participate in a regional process of status competition among Bali Aga villages, and also reflects their efforts to establish a degree of political unity among themselves vis-a-vis the outside world.

Graeme MacRae's paper (Chapter Four) complements this account of highland Balinese domains by exploring how such domains were built on in processes of state formation. MacRae examines inter-village networks of ritual association that have been brought into the context of a traditional Balinese state, the Kingdom of Ubud. South Balinese traditional culture tends to be seen, in the mainstream of local society and in scholarly studies, as originating in Majapahit Java and ultimately in Indic culture. A close examination of ideas and practices to do with land and landscape, however, suggests greater commonalities with other Austronesian societies. The paper examines the interface between these Austronesian and Indo-Javanese dimensions of southern Balinese ideas of land and landscape. MacRae also considers transformations of this landscape in the wake of Dutch colonialism, Indonesian independence and the more recent internationalisation of Bali's political economy.

In his paper (Chapter Five), Phillip Winn describes a rather unusual case. He shows how the idea of a 'blessed land' (tanah berkat) has helped to define the Banda Islands as a 'shared destination' for migrants from different ethnic origins, rather than as a 'shared origin' site with a set of indigenous custodians. Despite the diverse historical origins of the contemporary population - who were brought to the Banda Islands by the Dutch after their original inhabitants had been killed or dispersed - a similar sense of shared identity and moral community is conveyed by such narratives of immigration. In a conjuncture of land (tanah) and local tradition (adat tanah), the roots of moral community are envisaged as existing in place. Tanah itself is viewed as eliciting, endorsing and enforcing moral practice through the actions of Muslim founder-spirits and through people's membership of a traditional village (negeri adat). This model of society has facilitated social participation irrespective of ethnic divisions.

In her paper 'Mapping Buru: The politics of Territory and Settlement on an Eastern Indonesian Island' (Chapter Six), Barbara Dix Grimes begins by exploring small territorial units known as fena, which she identifies as a reflex of the Proto-Austronesian *benua. On Buru, there is a strong relationship between particular fena and the 'origin group' (noro) considered to be the traditional owners of that land. In any one settlement, one clan is usually dominant numerically and socially. Thus the territorial concept fena and the social category noro become almost interchangeable, even though, usually, some fena residents are immigrants. There is no evidence for any territorial organisation larger or more complex than the fena in the sparsely populated interior of Buru, except for some references to regional clusters such as the seven fena (fenar pito) that 
comprise the regency of Masarete. The island was dominated politically by the small coastal kingdoms of Muslim immigrants who were later recognised by the Dutch as the rulers of Buru as a whole. More recently, much confusion has arisen from a lack of correspondence between fena and the territorial unit 'desa' which was introduced by the Indonesian Government.

Still within the Moluccas, Christine Boulan-Smit's paper looks at the structure of the hena among the Alune of West Seram (Chapter Seven). The 'Wele Telu Batai' ('Three Rivers') upland region of West Seram is divided into a number of territorial units occupied by Alune or Wemale communities of shifting cultivators. In modern Indonesia, these are designated as desa (villages) and kecamatan (subdistricts). In Alune, however, the smaller units are called hena, and alliances of several hena along a river system are called batai (literally, 'tree trunks'). The paper describes how a hena is organised internally, particularly in relation to the origin group ( $n u r u$ ) who were its founders. As a territorial unit, the hena is a single body or entity, no section of which may be fenced, divided or sold. It is also a social unit aware of its origin, history and ritual duties, all of which are supported by narratives of origin. Boulan-Smit then describes how hena are linked together within the larger domain-like institution of the batai in a complex order of precedence. This status order is articulated through the seating order of hena representatives at customary meetings (nili ela), as they sit in a row from the trunk to the tip end of a ritually felled tree trunk (compare with Reuter, this volume, on orders of seating on the main beam of longhouses). The batai network as a whole is envisaged as a tree-like shape. Botanic metaphors are thus used as a signifier of precedence relationships. Batai also belong within even larger named regional clusters such as Wele Telu Batai.

In a seminal paper entitled 'From Domains to Rajadom: Notes on the History of Territorial Categories and Institutions in the Rajadom of Sikka' (Chapter Eight), Douglas Lewis discusses a historical process that is of general relevance to eastern Indonesia, whereby some societies gave rise to local states while others did not. For example, the Ata Tana Ai in the eastern part of Sikka in Flores never formed a secular polity but maintained a traditional division into five tana or 'ceremonial domains', which closely resembles the social organisation of highland Bali, Buru and Seram (see above). Central Sikka, however, developed a local state: a single polity under the rule of a royal house that originated in the Portuguese era and continued as a semi-autonomous state under the Dutch, not unlike the Kingdom of Ubud in Bali. Before the advent of the rajadom, Sikkanese lived in a domain-based society similar to the Ata Tana Ai. Lewis discusses what the domains of Sikka were like before the rajadom, how the Sikkanese rulers established their hegemony over central Sikka and what changes in territorial categories and institutions resulted from the evolution of domains into a rajadom. He concludes that Europeans played a significant role in, but did not cause, the development of local states in the region. Large-scale states such as Srivijaya, 
Majapahit and Mataram predated the arrival of Europeans in South-East Asia, and the societies of eastern Indonesia had long been involved with these kingdoms through maritime trade.

The merger of a large number of domains into a single polity required the people of Sikka to reconceptualise categories of territory. The scale of tana in central Sikka was small. Perhaps as many as 45 discrete tana coexisted in an area of no more than 700 square kilometres, and the tana, negeri and natar of the older Sikka had no boundaries. The shift to a new idea of territory as bounded landscape was thus significant. In the place of many centres of local, ritual authority, a polity was created in which the raja bore a singular political power over the older, more local centres. A new system of status and prestige came into being within which the authority and power of officers and ministers in the raja's government eclipsed those of the ritual leaders of the domains. The old offices of tana pu'ang and other ritual specialists survived, but - similar to the priests of some Bali Aga temples (Reuter 2002a) - their function came to be the legitimation of the new order.

Still concerned with Flores and with a case reminiscent of the Ata Tana Ai, Philipus Tule's paper is entitled 'We are Children of the Land: A Keo Perspective' (Chapter Nine). Tule describes Keo as a 'house-based society'. As in several of the preceding cases, the status of a clan house ( $\mathrm{sao}$ ) is defined by its positioning relative to other houses within a settlement or hamlet (nua, a reflex of *banua) and area of land (tana). The paper explores social and cosmological interconnections between tana, nua and $s a^{\prime} o$ among the Keo. Local participants speak of these interconnections in ritual speech as essential to maintaining a state of harmony, whereby 'the land is not shaky and stones are not trembling'. In keeping with this ideal, disputes over agricultural land and house land (dae sao) are mediated by the Lord of the Land ('ine tana ame watu) or other, lower-ranking leaders (mosa daki). Since Keo regard land as their mother and stone as their father, they reject the idea of individual ownership of ancestral land (tana ine embu, or tana suku). Only an individual affiliated with a source house (sao puu) and settlement (nua oda) has the right to cultivate such land. The social bond between people who share ancestral land is maintained through active participation in rituals related to the ancestral house and land.

In his paper 'Contending for Ritual Control of Land and Polity: Comparisons from the Timor Area of Eastern Indonesia' (Chapter 10), James Fox compares traditional categories of 'land', 'territory' and 'domain' across three closely related societies, and describes the ritual and political offices and ceremonies associated with these categories. The first case study examines categories of land and domain among the Rotinese, and is focused on the island's central domain (nusak) of Termanu. Termanu's elaborate origin narrative establishes a separation of political power and ritual authority by drawing a distinction between its 
newcomer ruler and a particular clan lord who holds the title of Head of the Earth (dae langak). The narrative illustrates a common Austronesian mythological theme whereby an 'outsider' is installed 'inside' and granted the right of rule. This theme is important in that it shows how Austronesians have mediated the land-related or other (material or symbolic) resource conflicts that frequently arose between earlier and later groups of migrating peoples.

The second case study concerns the Atoni Pah Meto of West Timor. Land (pah) is primary within the Atoni concept of identity and prominent in many of their traditional titles. Like the people of Flores and Roti, they have a long history of European contact but their political formations predate this period. Amanuban is the most important domain and became the dominant Atoni state in West Timor for a significant period during the 18th and 19th century. Houses (ume, uem) represent Atoni origin groups (kanaf) at the level of the local settlement. Settlements (kuan > Tetun, knua >PAN/PMP *banua) are significant not as ordered space but as a local stage for an ordering of precedence among particular kanaf.

Both cases are then compared with the Tetun of West Timor, whose major domain, Wehali, is regarded by many as the sacred centre of Timor as a whole. Wehali is rai feto, 'female land', as opposed to rai mane, 'male land', and is the traditional site of the Nai Bot/Kukun, 'The Great/Dark Lord'. The authority of this lord was once acknowledged through harvest rituals attracting delegations from a large area of Timor, including many Atoni domains. Similar to the botanic imagery of the origin myth mentioned in Boulan-Smit's paper on Seram, according to its origin myth, Wehali is a great banyan tree that offers shade to its constituent groups. The ordering of subgroups within this confederation follows a fourfold division, as among the highland Balinese. Wehali itself is known as the Rai Lidun Hat, Rai Sikun Hat: 'Four Corner Land, Four Section Land.' As on Roti and Bali, the land is envisaged as a body with its 'tail' to the west and its 'head' to the east. The general term for 'earth', 'land' or 'territory' among the Tetun is rai. An alternative term is rae, which is related to the Rotinese for earth, dae. On its own, rae has the sense of uncultivated 'land' rather than 'earth'. Within this scheme, Wehali is the rai hun, leo hun: 'Land of origin, Leo of origin.' Whereas among the Rotinese, a leo is a clan-like origin group defined by its position within a particular nusak or domain and thereby confined to that nusak, a leo among the population of Wehali is a named residential group - a hamlet - comprising specific named houses. The Tetun term for 'settlement' or 'village' outside of Wehali is knua ( $>$ *banua). Wehali has no knua and the term is used only in a metaphoric sense.

Andrew McWilliam's paper stays within the same region, and discusses Fataluku Forest Tenures and the Conis Santana National Park in East Timor (Chapter 11). McWilliam explores customary tenures and land-management 
practices in the context of an emergent government land policy in East Timor's most easterly district, Lautem. During the period of Indonesian rule in East Timor (1975-99), much of the forested zone was classified as a 'natural conservation reserve'. On paper at least, this prohibited logging and other forms of extractive activity. Under the United Nations Transitional Administration in East Timor (UNTAET) from 1999, the area was reclassified as a 'Protected Wild Area', and, in 2002, through its Directorate of Forestry, the independent East Timor Government initiated a program to demarcate the area as the country's first National Park. The prospects for the successful establishment of the park are in question due to the contested status of the region. This ownership issue arises because the greater part of the forested zone in this proposal is not composed of old-growth forest. Rather, the forest is a mosaic of former swidden gardens and settlement sites. Customary tenures and local claims of Fataluku-speaking populations to the forestry zone remain intact. As a result of consultations with community leaders, government forestry staff informally acknowledge the existence of 'traditional land' (Bahasa Indonesia: tanah adat) in the park area, but there is no formal agreement, at this stage, on the prospective status of their ownership claims. Nor has there been any sustained study of the ethnographic context within which these claims emerge. This paper offers a preliminary contribution towards this end.

The focus moves beyond Indonesia with Mark Mosko's paper (Chapter 12), entitled Self-Scaling the Earth: Relations of Land, Society and Body Among North Mekeo, Papua New Guinea'. The territorial categories in the language of North Mekeo (the PNG/Western Papua Tip cluster of Western Oceanic) are pangua or paunga ('village') and ango ('land' or 'territory'). The paper investigates these terms in relation to indigenous conceptualisations of society that employ body metaphors and a systematic fourfold pattern of 'inside-outside' (aongai-fangai) distinctions. Such spatial metaphors and associated fourfold divisions of society are widespread in the Austronesian world. North Mekeo classify land, body and society through analogous classificatory and procedural (temporal) mechanisms in terms of inside/outside distinctions and transactions, which consist formally of relations of self-similar or fractal scaling. Consequently, the three contexts of 'land', 'body' and 'society' can be seen as constituting a single semantic domain.

John P. Taylor's paper, 'The Ways of the Land-Tree: Mapping the North Pentecost Social Landscape' (Chapter 13), examines concepts of land and place, and their relationship to land-use practices, in the region of North Pentecost, Vanuatu, which belongs to the Raga language group. The paper begins by identifying important local delineations of territory and geography (vanua, tano, uma) and related concepts of social or personal emplacement (bwat) and movement (hala). Such concepts are pivotal for defining kinship-related patterns of settlement, land use and social organisation. As in Seram, Wehali and elsewhere 
in the region, botanic metaphors are used to describe relationships between places. This is illustrated beautifully with a tree-like map drawn by a local informant to show how territories are connected through a history of human movement. With reference to the hamlet cluster of Gelau, the paper describes the emergence of such patterns from their early beginnings, through colonial transformation to the present.

Mary Patterson's paper (Chapter 14) is entitled 'Finishing the Land: Identity and Land Use in Pre and Post-Colonial North Ambrym'. Land and place categories in northern Vanuatu show a distribution that tends to feature one or the other of the vanua and tan terms. Both words might be present, but if vanua is prominent in local discourse then tan is not, and vice versa. In Ambrym and South Pentecost there appears to be no reflex of vanua. In Vao Island north-east of Malakula, however, venu and vanu refer to a 'village' or 'place' and in mainland Malakula vene appears as part of clan names. Similarly in Malo, tan appears as part of clan names. In East Ambae, vanue is important but tano less so. Vanue is not just land (tano), it is lived space in which place and people are part of each other.

In North Ambrym, conflict over land use and alienation at the local and national level has given rise to a new rhetoric of connections to land that employs Austronesian territorial categories with a complex history, now refracted through the lens of post-colonial identity politics. The paper examines the North Ambrym context, where novel ways of making status claims are in effect a dynamic refiguring of autochthonous and reticular connections to territory near and far, which appear in mythological and ritual contexts.

Steve Francis's paper 'People and Place in Tonga: The Social Construction of Fonua in Oceania' (Chapter 15), provides an important comparison with a society in Polynesia. The author examines the usage of the term fonua ('land/people') as a territorial and social category in the Kingdom of Tonga. Fonua, a reflex of the Proto-Austronesian reconstruction *banua, is an important marker of local belonging as well as regional identity in Tonga. Francis shows how modern Tongans employ this social category in varying political, economic and social contexts; political in the sense of elite-commoner relations, economic in the context of land use and landownership, and social within the framework of village, island, regional and national identities. Fonua is used as an inclusive social and territorial concept, which incorporates links between local and global scales, the physical and metaphysical, the land and the sea. These links are illustrated through an examination of myth, history, social relations and local boundaries.

In sum, the papers in this volume illustrate the wealth of cultural diversity and important recurrent themes in how Austronesians have conceptualised the dynamic relationships between people and land. Local models of human 
movement and emplacement reveal a reflexive awareness of the conflicting human tendencies towards mobility and localised interests. They address issues of legitimacy in relation to territorial claims by linking them to cultural constructs of social identity, which, in the Austronesian world, are focused primarily on narrative histories of human movement. These models of society are not prone to primordialism but are instead founded on a celebration of the historicity of human society as a living, growing entity. In this world view, territorial and social categories are often closely interlinked. Founders and newcomers (who are often also affines) are afforded a place in Austronesian cosmological models, and their harmonious interaction is seen as no less integral to society than male and female is to the perpetuation of life itself.

\section{Contemporary Issues and New Directions in Comparative Austronesian Studies}

The continuing relevance of Comparative Austronesian Studies for understanding the way of life of contemporary Austronesian-speaking populations cannot be taken for granted. Are Austronesian societies still similar and, at the same time, diverse enough in this 21 st century to permit a meaningful comparison? And, if so, is their similarity still based predominantly on a shared cultural heritage or is it on account of their having been similarly subjected to the presumably homogenising influences of colonialism, modernity and globalisation? Or, alternatively, are there any thematic issues in the contemporary Austronesian world that are best understood in terms of an interaction between the influences of a regional cultural heritage and a new, global form of cultural homogeneity?

The evidence suggests that 'traditional' organisational and conceptual patterns derived from a common Austronesian heritage have not become irrelevant. Nor should we ignore the growing dependence of Austronesian-speaking societies on a global capitalist economic system, which does have a homogenising influence on culture, or at least on consumer culture and technology. Both factors seem to be exerting an influence on the cultural trajectory of the Austronesian world. The difficulty, however, lies in the fact that they might do so in fundamentally different ways. Extending Norbert Elias's (1969) historical theory on the rise of modernity, one could argue that the postmodern form of cultural similarity is based no longer on a common heritage, which assumes a process of branching out from a common historical origin, but, quite to the contrary, on an ever-tightening web of socioeconomic interdependencies drawing different cultures inward into the whirlpool of a centrifugal and homogenising world system.

There is no debating the rapid internationalisation that is taking place in the world today. Anthropologists and others with an appreciation for cultural diversity, however, may often feel dismayed at examples they encounter in the public domain of an extreme globalisation perspective on current affairs. As 
Friedman (1997: 269) points out, 'Notions of globalisation, hybridisation, and creolisation are socially positioned concepts that in their classificatory thrust say very much about the classifiers and much less about those classified." For example, many political commentators seem to be looking at places like Indonesia once again through Western eyes, as still imperfect replicas of Western democratic nation states, destined to become more and more 'perfect' and hence more transparent to our understanding in the course of globalisation, either naturally or, if need be, with some benevolent intervention here and there. In adopting this new universalist model of a singular future for humanity, the presumably culture-less Western centre of the global system regards 'culture' as a non-Western phenomenon that is increasingly and quickly becoming irrelevant. And whenever the 'locals' provide evidence to the contrary by asserting their tradition, the response is to classify their self-representations as neo-traditionalism, primordialism or some other futile revivalist attempt at reimagining and reinstating a long-lost past. And if they assert their right to be different violently, the problem must be contained by force. 'We', who are already posturing as the defining force of 'their' past - by reducing that past to a history of colonial domination - are now projecting our vision of ourselves into their future, by casting ourselves as the carriers of the universal model of a global, postmodern way of life to which they must inevitably conform. If there is some truth to this popular perspective on globalisation at all, then the process of cultural and political imperialism it alludes to is not necessarily one that should be further encouraged in social science by depicting it as natural and inevitable.

Anthropologists need to challenge reductionist perspectives on globalisation and associated assumptions about cultural homogenisation by highlighting the contrary, localising and diversifying forces that also shape trajectories of socio-cultural change. The preceding comparative analysis has shown some of these contrary forces at work among related societies across a vast region. It has done so by highlighting how changes in local, historical and situational conditions over several millennia have contributed to the cultural diversity of the Austronesian world. At the same time, several of the case studies also allude to the centrifugal or homogenising force of growing interdependence-from complex village societies with clan groups of variable origins, to early state formation, to the rise of modern nations - suggesting that these centrifugal processes are not a new phenomenon. In order to remain viable well into the future, the Comparative Austronesian Studies Project will need to develop methods to identify emergent and centrifugal forms of similarity as well as trends towards new patterns of variation among contemporary Austronesians. This volume is taking some important first steps in this direction. 


\section{References}

Appadurai, A. 1988. 'Putting Hierarchy in its Place.' Cultural Anthropology, 3. pp. 36-49.

Bellwood, P., J.J. Fox and D. Tryon (eds). 1995. The Austronesians; Historical and Comparative Perspectives. Comparative Austronesian Studies Project. Canberra: The Australian National University.

Clifford, J. 1988. The Predicament of Culture: Twentieth-Century Ethnography. Cultural Anthropology 7. pp. 6-23.

Elias, Norbert. 1969. Über den Prozess der Zivilisation: Soziogenetische und psychogenetische Untersuchungen. 2 Volumes. Bern (Switzerland): Francke AG.

Gupta, A. and J. Ferguson. 1992. Beyond 'Culture': Space, Identity, and the Politics of Identity. Durham and London: Duke University Press.

Fox, James J. 1980. 'Introduction.' In J.J. Fox (ed.), The Flow of Life: Essays on Eastern Indonesia, Cambridge (Mass.): Harvard University Press. pp.118.

Fox, James J. (ed.) 1993. Inside Austronesian houses: Perspectives on domestic designs for living. Comparative Austronesian Studies Project. Canberra: The Australian National University.

Fox, James J. (ed.) 1997. The Poetic Power of Place: Comparative perspectives on Austronesian ideas of locality. Comparative Austronesian Studies Project. Canberra: The Australian National University.

Fox, James J. and Clifford Sather (eds). 1996. Origins, Ancestry and Alliance; Explorations in Austronesian ethnography. Department of Anthropology, Research School of Pacific and Asian Studies, Comparative Austronesian Studies Project. Canberra: The Australian National University.

Friedman, Jonathan. 1997. 'Simplifying Complexity: Assimilating the global in a small paradise.' In Karen F. Olwig and Kirsten Hastrup (eds), Siting Culture: The shifting anthropological subject, London and New York: Routledge.

Geertz, C. 1980. Negara: The Theatre State in Nineteenth-Century Bali. Princeton (N.J.): Princeton University Press.

Lavie, S. and T. Swedenburg (eds). 1996. Displacement, Diaspora, and Geographies of Literature, and Art. Cambridge: Harvard University Press.

Malkki, L. 1995. 'Refugees and Exile: From 'Refugee Studies' to the National Order of Things'. Annual Review of Anthropology, 24. pp. 495-523.

Marcus, G.E. 1993. 'Tonga's Contemporary Globalizing Strategies: Trading on Sovereignty Amidst International Migration.' In V.S. Lockwood, T.G. 
Harding and B.J. Wallace (eds): Contemporary Pacific Societies. Studies in Development and Change, Engelwood: Prentice Hall. pp. 21-33.

Olwig, Karen F. and Kirsten Hastrup (eds). 1997. Siting Culture: The shifting anthropological subject. London and New York: Routledge.

Reuter, Thomas A. 1999. 'People of the Mountains - People of the Sea: Negotiating the Local and the Foreign in Bali.' In L.H. Connor and R. Rubinstein (eds), Staying Local in the Global Village: Bali in the Twentieth Century, Honolulu: University of Hawai'i Press.

Reuter, Thomas A. 2002a. Custodians of the Sacred Mountains. Honolulu: Hawai'i University of Hawai'I Press.

Reuter, Thomas A. 2002b. The House of Our Ancestors. Leiden: KITLV Press.

Vischer, Michael P. (ed.) In press. Precedence: Processes of Social Differentiation in the Austronesian World. Canberra: Comparative Austronesian Studies Project, Research School of Pacific and Asian Studies. Canberra: The Australian National University. 